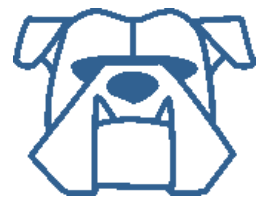

Kettering University Digital Commons @ Kettering University

6-15-2019

Increasing the Interest of Elementary School Girls in STEM Fields Through Outreach Activities

Jennifer Bastiaan

Roger Bastiaan

Follow this and additional works at: https://digitalcommons.kettering.edu/mech_eng_conference

Part of the Education Commons, and the Engineering Commons 


\section{Increasing the Interest of Elementary School Girls in STEM Fields Through Outreach Activities}

\section{Dr. Jennifer M. Bastiaan, Kettering University}

Jennifer Bastiaan received her Ph.D. in Mechanical and Mechatronics Engineering from the University of Waterloo. She is an Assistant Professor in the Mechanical Engineering department at Kettering University, where she is focused on teaching and research in ground vehicle systems. She is a veteran of the U.S. automotive industry with two decades of experience, including modeling and physical testing programs. Her technical research interests include vehicle dynamics, tire mechanics, and sound and vibration. She is also interested in education research, especially regarding the design of engaging STEM outreach programs for pre-college students, and the incorporation of effective industry partnerships into undergraduate engineering education.

\section{Mr. Roger Bastiaan, ENWIN Utilities}

Roger Bastiaan is the Supervisor of System Control at ENWIN Utilities, a public electric power company in Ontario, Canada. He has three decades of electric system control experience. He is interested in the education and training of future generations of employees in the power industry. 


\title{
Increasing the Interest of Elementary School Girls in STEM Fields Through Outreach Activities
}

\begin{abstract}
Despite the known value of a diverse STEM workforce, women and minorities continue to be under-represented in STEM fields. Engineering undergraduate degrees, in particular, are awarded to women and minority engineering students in North America at a lower rate compared to their male counterparts. Research has shown that low self-confidence in learning math and science subjects starts at a young age in girls and minority students, often in the early years of elementary school, and this ultimately leads to low interest and enrollment in STEM undergraduate programs. In an attempt to combat negative stereotypes about the capabilities of girls and minorities in STEM studies, which undermine the confidence of these groups, the Society of Women Engineers has instituted the Girls' Engineering Exploration day. This is an annual, all-day STEM outreach event for elementary school girls in the Detroit Public School system. Groups of girls participate in the event with volunteer mentors who are female engineers working in local industry, thus providing the girls with role models. The groups of girls and their mentors cycle through a series of STEM activities that are meant to be fun and engaging, and to increase their interest in STEM careers. In this work, two Girls' Engineering Exploration activities recently created and presented are described in detail, a traditional electrical circuits activity and an original autonomous vehicles activity. All of the materials for both activities are provided as educational resources, such that pre-college educators can take advantage of these activities in their own classrooms and outreach events with little to no modification. Furthermore, the results of student surveys from the activities are analyzed and presented. The conclusion is that modern topics such as autonomous vehicles are well worth the activity development effort, as students are more engaged in these activities than in derivative exercises such as the circuits activity, which they may have been exposed to previously.
\end{abstract}

\section{Introduction}

For the past 20 years, less than $20 \%$ of engineering degrees in the United States and Canada have been awarded to women students, and this stubborn trend is not changing much [1,2]. The outcome is worse for black and Hispanic students, who usually comprise less than $10 \%$ of engineering graduates $[3,4]$. The lack of enrollment and graduation of female and minority students in STEM programs has traditionally led to a STEM workforce that lacks diversity [5-9]. To address this lack of diversity, the Society of Women Engineers (SWE) has instituted the Girls' Engineering Exploration (GEE) day. GEE is an annual STEM outreach event for elementary school girls, especially minority students. The objective of GEE is to increase interest in STEM fields among the girls who participate in the event, along with increasing their self-confidence in successfully performing STEM activities. Traditionally, girls have more negative attitudes and anxieties toward STEM compared to boys [10]. Ultimately, the goal of GEE is to reverse this trend, and to increase female and minority enrollment in STEM undergraduate programs, which will result in greater participation of these groups in the STEM workforce. 


\section{Related Work}

In their research study of a science curriculum designed for middle school students, Guzey et al. [11] noted the critical importance of providing opportunities for students to explore engineering in order to increase interest and achievement in STEM fields. This is precisely the kind of exploration that GEE is designed to deliver. Results from the literature have shown that inclusion of female role models into GEE and similar outreach events is highly desirable, as exposure to such role models is known to increase STEM interest among girls. Several outreach events and similar education programs are described in the literature, with most reporting increased STEM knowledge and interest among participating girls. Interestingly, the majority of research studies related to STEM outreach have middle school students as participants. However, the results of several studies show that girls should be exposed to STEM in the 10 to 13 years old age range, when career goals are still undecided. It is this younger group of girls that receives the attention of GEE.

\section{STEM Role Models}

Lee and Anderson [12] found that middle school students were about three times more likely to name a male mathematical role model than a female mathematical role model. Students were asked to name someone they know who is really interested in mathematics. Responses showed a clear male gender bias, suggesting that more female role models are required. Along these lines, Hughes et al. [13] investigated two middle school science programs; the results showed that increased STEM interest in girls was related to exposure to positive STEM role models.

Schnittka and Schnittka [14] investigated an after school STEM program that took place in a rural community. Both girls and boys participated in the program. Recommendations from the study included the addition of team building activities prior to group work, and the incorporation of engineering role models who understand the male dominated engineering culture. Wyss et al. [15] examined the impact of informing middle school students about STEM careers through the use of video interviews with STEM professionals. Results showed that making students aware of STEM careers by providing knowledge about STEM professions increased their interest in pursuing their own STEM careers.

\section{STEM Outreach and Education}

Levine et al. [16] designed and deployed a one week long STEM outreach camp for middle school girls at the University of Rhode Island that featured chemistry activities. The camp included interactions with female science faculty from the sponsoring institution, as well as meetings with female undergraduate and graduate students. Surveying methodology was used to evaluate the effectiveness of the camp with respect to influencing the attitude of the participants toward pursuing STEM careers. The participant girls' interest in STEM occupations increased over the time-frame of the camp, which is noteworthy since the camp lasted for only one week. These results suggest that even short-term STEM outreach events can make females more likely to pursue STEM careers.

Kim [17] investigated a one week long STEM enrichment program for middle school girls at a Midwestern university in the United States, which had the goal of increasing female students' 
interest in science. Students worked in groups on guided activities that included collecting data, recording results, and analyzing findings. Likert-style surveys were used to determine attitudes about science among the participating girls. Results showed that there were significant improvements in scientific knowledge in the girls after completion of the program, as well as increased interest in STEM. Christensen and Knezek [18] performed a study of more than 800 middle school students, which found that hands-on science activities are particularly effective in increasing STEM career interest in middle school girls.

\section{Age of Intervention}

Tan et al. [19] pointed out that career aspirations are to a large extent formed before age 13; beyond this age it is increasingly difficult to engage students in STEM. Further results showed that formative experiences in the ages of 10 to 13 years old are crucial to supporting interest in STEM fields, especially for girls. In a relatively uncommon study from Wood et al. [20], in the sense of targeting younger $4^{\text {th }}$ and $5^{\text {th }}$ grade girls, an after school science program was implemented. The authors emphasized that science instruction should being early, before a gender gap emerges. Thus, students should be given an opportunity to explore STEM careers before middle school.

\section{GEE STEM Outreach Event}

GEE is a STEM outreach event organized by SWE. Held once per year in the winter since 2008, GEE is designed for $4^{\text {th }}$ to $6^{\text {th }}$ grade female students in the Detroit Public School (DPS) system, with the ultimate objective of increasing interest and enrollment in STEM undergraduate programs among these students. DPS students come mostly from economically disadvantaged communities; furthermore, they are 95\% black and Hispanic [21]. Female students of color, especially those from low-income families, are known to be under-represented in STEM undergraduate programs, as well as in STEM fields. Thus, the GEE program is part of a broader effort to increase the diversity of the STEM workforce. GEE exposes girls to STEM careers through interactive demonstrations and hands-on activities. The activities require participating girls to be creative, innovative, and to exercise problem-solving skills. Activities are designed to encourage teamwork.

Each GEE event normally hosts around 100 girls; the total number of participants is divided into smaller groups of about five girls. These smaller groups take part in GEE with volunteer mentors, who are female STEM professionals working in local industry and academia. Each sub-group of five girls is assigned one or two female mentors. Thus, the event provides participating girls with direct access to female STEM role models. The groups of girls and their mentors cycle through a series of activities that are meant to be fun and engaging, and to increase their interest in STEM careers. GEE is held at the Michigan Science Center [22], which is a not-for-profit museum dedicated to the appreciation of STEM in a creative and dynamic learning environment. Figure 1 shows photographs from the 2017 and 2018 GEE events.

GEE activities are varied each year, without repeat activities from previous years. This is because

quite a few participating girls attend the event in the $4^{\text {th }}$ through $6^{\text {th }}$ grades that they are eligible; that is, they attend for all three years. As repeat activities would be boring for the girls, new activities are created each year, to maintain their interest in both the GEE event and STEM in 


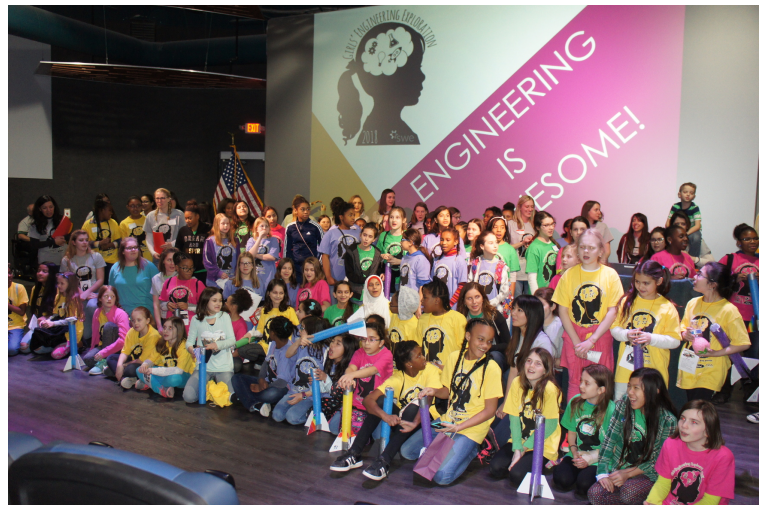

(a) Group Assembly in 2018

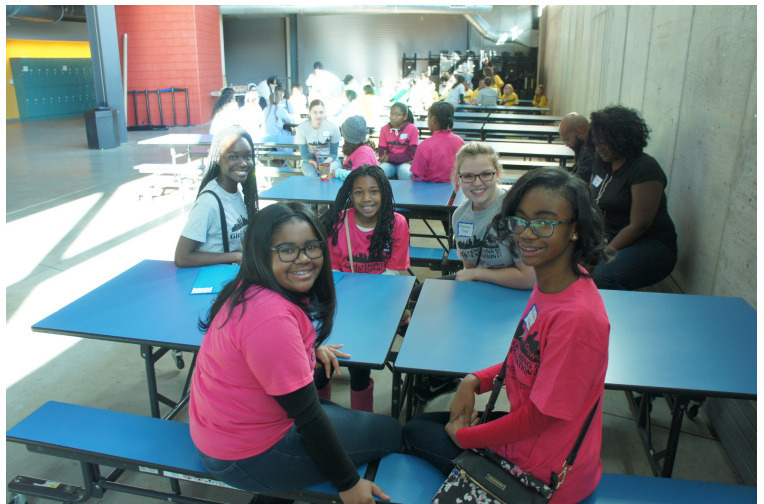

(b) Lunch Room in 2017

Figure 1: GEE Event Photographs

general. Each GEE activity is designed to last for approximately 25 minutes. A typical GEE event day is shown in Table 1. Girls are provided with T-shirts printed with the GEE logo on the day of the event. Different color T-shirts identify different groups of participants. Colors listed in Table 1, therefore, refer to T-shirt colors. Volunteers are also given special event T-shirts, but the color of the volunteer T-shirts differs from any color worn by the girls, for easy identification of volunteers and participants.

All GEE activities are designed by volunteers, and the event itself is organized entirely by volunteers. Each yearly event requires about eight months of planning. Usually around 75 volunteers plan and execute the event. No volunteer is compensated for organizing or managing the event. The total cost for each activity is limited to a few hundred dollars (USD), due to budget constraints on the event. GEE is funded by donations from corporate sponsors and partners. The event is free to participating girls; registration is performed using an online form. GEE is advertised to DPS female students by their teachers, who are given materials and details in advance of the event. At the end of the event, participating girls receive complimentary T-shirts and backpacks stuffed with school supplies and mementos including a take-home activity.

\section{GEE STEM Activities}

Detailed information about the design and deployment of two GEE STEM activities is reported, including cost of required materials. Sufficient information is provided such that pre-college educators can use the activities directly in their classrooms. Worksheets and science sheets are provided in Appendix A. Activity procedures and interactive lectures given by the activity leader are provided here, both to illustrate the nature of the activities, and to supply detailed instructions to pre-college educators who may wish to use the activities.

\section{Fun With Circuits Activity}

The first activity is a traditional engineering exercise involving physical creation and observation of electrical circuits; it was based on the "completing the circuit" activity available from the TeachEngineering database of K-12 STEM curriculum resources [23]. Fun With Circuits was 
Table 1: Typical GEE Outreach Event Schedule

\begin{tabular}{|c|c|c|c|c|}
\hline Start Time & Duration & Pink Group & Green Group & Yellow Group \\
\hline 7:45 A.M. & $15 \mathrm{~min}$ & \multicolumn{3}{|c|}{ Volunteer Check-In } \\
\hline 8:00 A.M. & $45 \mathrm{~min}$ & \multicolumn{3}{|c|}{ Setup } \\
\hline 8:45 A.M. & $45 \mathrm{~min}$ & \multicolumn{3}{|c|}{ Participant Check-In } \\
\hline 9:30 A.M. & $20 \mathrm{~min}$ & \multicolumn{3}{|c|}{ Welcome Presentation: All Participants } \\
\hline 9:50 A.M. & $30 \mathrm{~min}$ & \multicolumn{3}{|c|}{ Split into Groups / Icebreaker Activity } \\
\hline 10:20 A.M. & $10 \mathrm{~min}$ & \multicolumn{3}{|c|}{ Move to Sparks Theater } \\
\hline 10:30 A.M. & $20 \mathrm{~min}$ & \multicolumn{3}{|c|}{ Attend Sparks Electricity Show: All Participants } \\
\hline 10:50 A.M. & $5 \mathrm{~min}$ & \multicolumn{3}{|c|}{ Move to GEE Activity } \\
\hline 10:55 A.M. & $25 \mathrm{~min}$ & Activity 1 & Activity 2 & Activity 3 \\
\hline 11:20 A.M. & $5 \mathrm{~min}$ & \multicolumn{3}{|c|}{ Move to GEE Activity } \\
\hline 11:25 A.M. & $25 \mathrm{~min}$ & Activity 4 & Activity 3 & Activity 2 \\
\hline 11:50 A.M. & $5 \min$ & \multicolumn{3}{|c|}{ Move to Lunch } \\
\hline 11:55 A.M. & $30 \mathrm{~min}$ & \multicolumn{3}{|c|}{ Lunch } \\
\hline 12:25 P.M. & $5 \mathrm{~min}$ & \multicolumn{3}{|c|}{ Move to GEE Activity } \\
\hline 12:30 P.M. & $25 \mathrm{~min}$ & Activity 3 & Activity 4 & Activity 1 \\
\hline 12:55 P.M. & $5 \mathrm{~min}$ & \multicolumn{3}{|c|}{ Move to Planetarium } \\
\hline 1:00 P.M. & $20 \min$ & \multicolumn{3}{|c|}{ Watch Planetarium Show: All Participants } \\
\hline 1:20 P.M. & $5 \mathrm{~min}$ & \multicolumn{3}{|c|}{ Move to GEE Activity } \\
\hline 1:25 P.M. & $25 \mathrm{~min}$ & Activity 2 & Activity 1 & Activity 4 \\
\hline 1:50 P.M. & $10 \mathrm{~min}$ & \multicolumn{3}{|c|}{ Move to Museum Exhibits } \\
\hline 2:00 P.M. & $55 \mathrm{~min}$ & \multicolumn{3}{|c|}{ Free Time at Museum Exhibits: All Participants } \\
\hline 2:55 P.M. & $5 \mathrm{~min}$ & \multicolumn{3}{|c|}{ Move to Closing } \\
\hline 3:00 P.M. & $30 \mathrm{~min}$ & \multicolumn{3}{|c|}{ Closing Presentation: All Participants } \\
\hline 3:30 P.M. & $30 \mathrm{~min}$ & \multicolumn{3}{|c|}{ Clean-Up } \\
\hline
\end{tabular}


used at the GEE 2017 outreach event. Photographs from this activity appear in Figure 2. Per kit cost for the activity appears in Table 2. Two girls were assigned to one kit during GEE 2017.

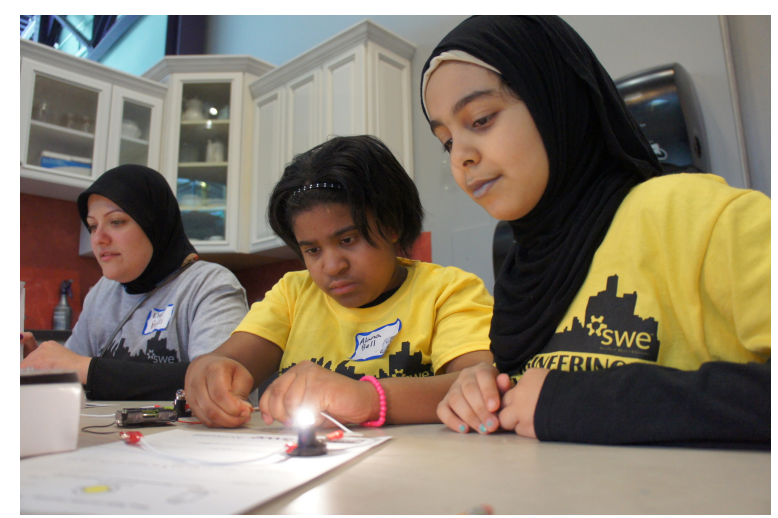

(a) Girls Building a Circuit

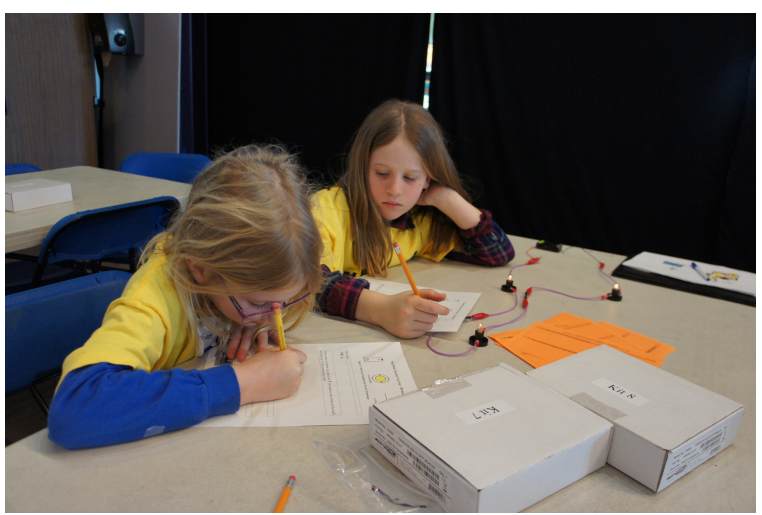

(b) Girls Filling Out Worksheets

Figure 2: Fun With Circuits Activity

Table 2: Fun With Circuits Per Kit Cost (USD)

\begin{tabular}{ccc}
\hline Quantity & Item & Cost \\
\hline 1 & AA Battery Holder & $\$ 0.43$ \\
\hline 1 & AA Battery & $\$ 0.25$ \\
\hline 3 & Miniature Light Bulb & $\$ 2.33$ \\
\hline 3 & Light Bulb Holder & $\$ 1.95$ \\
\hline $4.5 \mathrm{ft}$ & 20 Gauge Wire & $\$ 1.08$ \\
\hline 8 & Alligator Clip & $\$ 1.77$ \\
\hline & TOTAL & $\$ 7.81$
\end{tabular}

\section{Fun With Circuits Procedure}

The introduction is given to the students assembled as a group. Questions for the students are listed with a "Q" symbol. Comments are marked with bullets. The instructor leads the activity throughout, announcing each step and making sure that all student groups have completed the step before proceeding with the next step.

\section{INTRODUCTION}

Q: Have you ever changed a light bulb?

Q: Why did you change the light bulb?

Q: What happened when the new light bulb was put in the lamp?

- When a light bulb is burned out, it does not light because the lamp's circuit is open (draw an open circle on the board, one that does not connect the end to the beginning). 
- When a new light bulb is placed in the lamp, the lamp's circuit is closed and electrons can move around the circuit (draw a closed circle on the board).

Q: Have you learned about atoms in school yet?

- Atoms are made of smaller particles; one of them is electrons. The flow of electrons in a material is called electric current.

- During our activity today, you will discover that a flow of electrons is needed to light a bulb. You will also learn what an electric circuit is.

Q: Do you have any electric circuits in your house?

Q: Who designs these electric circuits?

- It is engineers who design electric circuits that are in the devices and appliances that we use every day.

\section{ACTIVITY}

1. Ask the students to find a partner, as the activity will be performed in groups of two.

2. Give one Fun with Circuits kit to each pair of students; each kit will be contained within a zipper storage bag.

3. Ask the students to connect the battery, one light bulb, and wires so the bulb lights up.

4. Ask the students to observe the brightness of the one light.

5. Ask the students to connect the battery, two light bulbs, and wires so the bulbs light up.

6. Ask the students to observe the brightness of the two lights.

7. Ask the students to connect the battery, three light bulbs, and wires so the bulbs light up.

8. Ask the students to observe the brightness of the three lights.

9. Ask the students to complete the worksheet in pairs.

10. Ask the students to disconnect all the components of their kit and return them to their bag.

\section{Autonomous Vehicles Activity}

The second activity is an original exercise centered on the new discipline of autonomous vehicle design. The Autonomous Vehicles activity was used at the GEE 2018 outreach event.

Photographs from this activity appear in Figures 3 and 4. The girls experimented with "doodle track cars", which are inexpensive toy cars that stand in for self-driving vehicles. These toy cars are equipped with optical sensors which enable them to follow hand-drawn lines that represent the roadway. This activity allows the girls to investigate the limitations of real sensors. Per kit cost for the activity appears in Table 3. Two girls were assigned to one kit during GEE 2018.

\section{Autonomous Vehicles Procedure}

The introduction to this activity should be presented to the participants as a group prior to beginning the activity. The introduction will be interactive. Questions for the students are listed with a "Q" symbol. Comments or further lines of questioning are marked with bullets. The instructor will lead the activity throughout, announcing each step and making sure that all groups have completed the step before proceeding with the next step. Project, show on a large poster 
GEE 2018: Autonomous Vehicles Activity
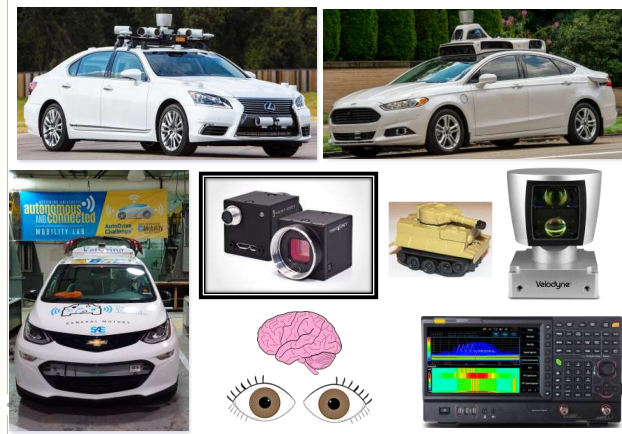

(1) $1 / 4$

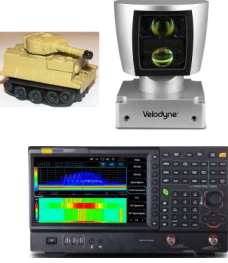

(a) Example Slide for Interactive Lecture

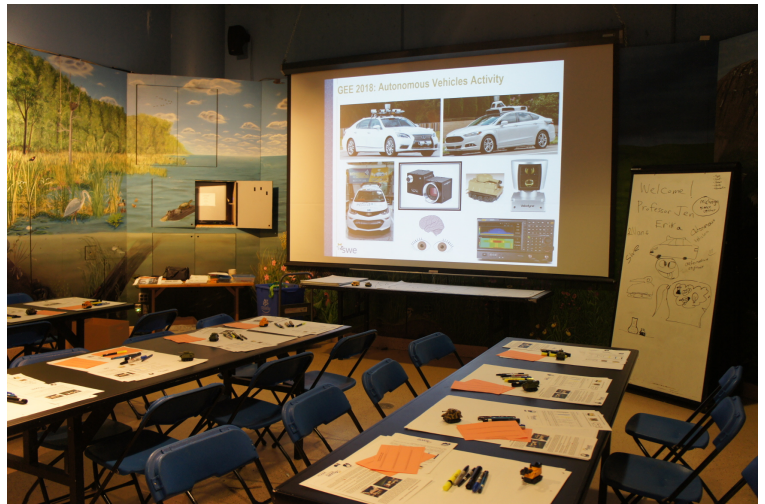

(b) Room Ready for Activity

Figure 3: Autonomous Vehicles Activity Setup

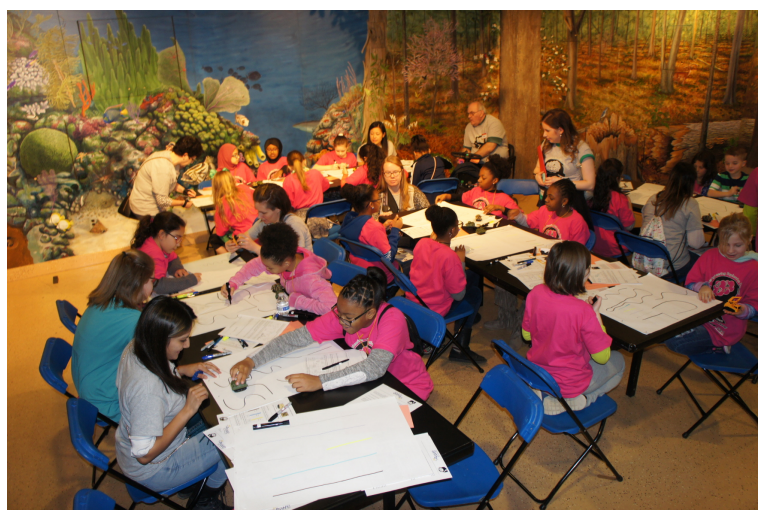

(a) Pink Group Performing Activity

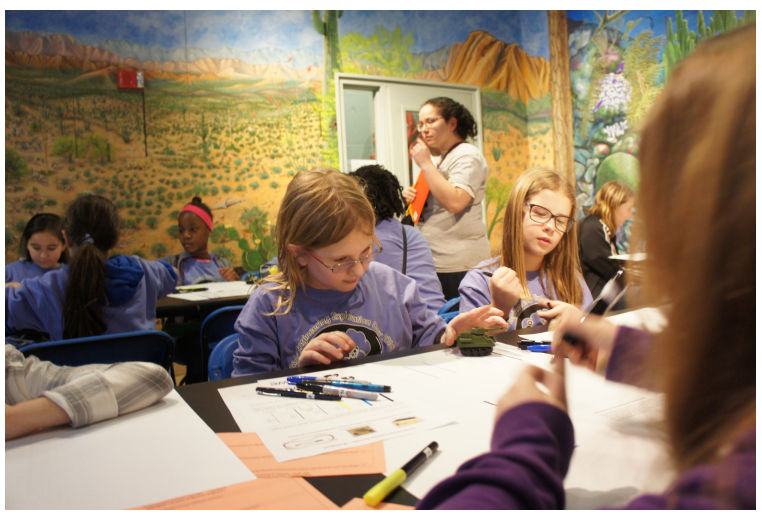

(b) Purple Group Performing Activity

Figure 4: Autonomous Vehicles Activity

Table 3: Autonomous Vehicles Per Kit Cost (USD)

\begin{tabular}{ccc}
\hline Quantity & Item & Cost \\
\hline 1 & Line Following Toy Car & $\$ 7.33$ \\
\hline 1 & Yellow Highlighter & $\$ 0.22$ \\
\hline 1 & Blue Highlighter & $\$ 0.31$ \\
\hline 1 & Blue Marker & $\$ 0.42$ \\
\hline 1 & Black Large Tip Marker & $\$ 0.56$ \\
\hline 1 & Black Fine Tip Marker & $\$ 0.56$ \\
\hline 1 & Black Marker & $\$ 0.44$ \\
\hline 3 & White Sheet of Paper (18 in $\times 24$ in or larger) & $\$ 0.39$ \\
\hline & TOTAL & $\$ 10.23$
\end{tabular}


board, or hand out copies of a slide showing various autonomous vehicles and components (see Figure $3 \mathrm{a}$ for an example). Be sure to have enough large tables or floor space to accommodate all of the participants.

\section{INTRODUCTION}

Q: Who has heard of autonomous vehicles or cars?

Q: Are there examples of any in this picture?

Q: What does an autonomous vehicle do?

Q: Thinking about a regular car, what human skills are required to drive a car?

Q: Without a person driving, these skills would have to be built into the car; so:

- How would the car see? What do you see with your eyes? Color, shape, size? What about distance? How about motion or speed or direction?

- Is there more than one way to see? Long distance, short distance, in the dark, behind, beside?

- How would the car think? How would it decide what to do?

- How would the car know where to go? What roads? How fast?

- Point out the LIDAR and camera units in the picture (associated with distance vision and object detection), explain that the signal analyzer represents the computing power needed in the vehicle, and that the eyes and brain represent some of the human talents needed to operate a vehicle. Mention that the toy car is autonomous; autonomous does not necessarily mean complex.

Q: Are there any other skills a human uses to drive a car? Hearing (ambulances, gusts of wind, train horns)? Feeling (car slipping on a road, how cold it is outside)?

- How about experience; that is, the collection of things you have learned? You see a playground and a ball sitting in the middle of the road; it is winter and it just started snowing heavily; it is summer and it just began pouring rain. What do you know about these situations?

Q: Who designs autonomous cars? What subjects would you need to study to design these vehicles?

- Engineers design autonomous cars. Almost every area of scientific study is involved in building the systems and the functions needed in an autonomous car - physics, optics, electricity, computer science ...

\section{ACTIVITY}

1. Ask the students to find a partner, as the activity will be performed in groups of two.

2. Give each group one materials kit including one autonomous toy car.

3. Ask the students to draw parallel straight lines on the paper provided using the six different pens in the kit.

4. Ask the students to test if the autonomous toy car can correctly follow each line. 
5. Ask the students to record if the car was able to follow the line drawn by the various pens. Select which pen created the best line for the car to follow.

6. Using the best pen, ask the students to draw five different curved lines on the paper provided.

7. Ask the students to test if the autonomous toy car can follow each curved line.

8. Ask the students to record the results. Ask them to consider the reasons why the car could or could not follow the various curved lines.

9. Ask the students to think of ways to improve the design of the autonomous toy car.

10. Ask the students to complete the worksheet in pairs.

\section{Major Results}

The effectiveness of the activities was measured through self-administered paper and pencil surveys. Surveys took the form of handwritten questionnaires filled out by the participants after each activity. Participation in the surveys at the end of the activities was entirely voluntary. Institutional Review Board (IRB) approval from Kettering University was obtained for these surveys. Parental permission forms were signed by parents / guardians in advance of the GEE events; these forms were deployed in an online / electronic format. Participants were not required to participate in the surveys, even if their parents / guardians had previously consented. Only willing participants completed the survey forms.

\section{Survey Questions}

Each activity, Fun With Circuits and Autonomous Vehicles, had a unique survey. The results of questions from the surveys form the basis of the data reported here. Survey questions were as follows; questions are listed as they appeared to the respondents on the surveys. The GEE 2017 survey was designed primarily to elicit responses that would result in improvements to the activity itself, through two short-answer questions. The GEE 2018 survey consisted of these same two questions, with slight modifications to refer to the activity itself. In addition, a third survey question was added to investigate the link between the activity and STEM undergraduate education that may (or may not) have been made by the participants. All of the survey responses provided qualitative data for evaluation purposes.

Fun With Circuits (GEE 2017)

1. What was your favorite part of the circuits activity?

2. What should be changed to make the circuits activity more fun?

\section{Autonomous Vehicles (GEE 2018)}

1. What was your favorite part of the autonomous vehicles activity?

2. What should be changed to make the autonomous vehicles activity more fun?

3. What subjects would you need to study in college in order to design an autonomous vehicle? 
Survey Analysis

Student responses to these questions were transcribed and inductively coded [24]. The responses were coded according to response categories that emerged during the data analysis. There were 50 valid surveys completed during GEE 2017. There were 78 valid surveys completed during GEE 2018. Table 4 lists eight categories developed during analysis of the first question asked in both activities, along with sample responses that illustrate the category from each activity. Note that the responses are presented exactly as they were written by the participants. Figures 5 and 6 show bar graph representations of the first question data for both activities in order of increasing frequency.

Table 4: Categories for Survey Question 1: What was your favorite part of the activity?

\begin{tabular}{|c|c|c|}
\hline Category & "Fun With Circuits" Sample Responses & $\begin{array}{l}\text { “Autonomous Vehicles" Sample } \\
\text { Responses }\end{array}$ \\
\hline Creation & "My favorite part was building the circuits." & "Making your own track." \\
\hline Everything & "Everything" & "Everything! ! ! ! !!!! !" \\
\hline Experimentation & $\begin{array}{l}\text { "I liked to connect the circuits and make the } \\
\text { light bulbs become dimmer \& brighter." }\end{array}$ & $\begin{array}{l}\text { "Testing out the car with lines, } \\
\text { and curves, and making } \\
\text { hypothesis \& conclusions." }\end{array}$ \\
\hline Learning & $\begin{array}{l}\text { "My favorite part of the activity was when we } \\
\text { learned why the battery has to evenly distribute } \\
\text { power to every circuit." }\end{array}$ & $\begin{array}{l}\text { "I liked learning about } \\
\text { autonomous vehicles." }\end{array}$ \\
\hline New Technology & N/A & "It's cool because I saw sencers." \\
\hline Observation & N/A & $\begin{array}{l}\text { "Drawing the random lines and } \\
\text { watching it go!" }\end{array}$ \\
\hline Participation & $\begin{array}{l}\text { "My favorite part was using the wire, light bulb, } \\
\text { and batteries to light up the light bulb." }\end{array}$ & $\begin{array}{l}\text { "My favorite part was being able } \\
\text { to make my own line, and test it." }\end{array}$ \\
\hline Teamwork & $\begin{array}{l}\text { "My favorite part of this activity is when my } \\
\text { group worked together to figure out how to turn } \\
\text { the light bulb on." }\end{array}$ & $\begin{array}{l}\text { "The activity because I love } \\
\text { working with other people." }\end{array}$ \\
\hline
\end{tabular}

Table 5 lists five categories developed during analysis of the second question asked in both activities, along with sample responses that illustrate the category from each activity. Note that the responses are presented exactly as they were written by the participants. Figures 7 and 8 show pie chart representations of the second question data for both activities. Eight categories were developed for the third question asked in the Autonomous Vehicles activity, which inquired about the subjects that would be required for study in college in order to design an autonomous vehicle. These categories are engineering, math, science, technology, computer science, physics, STEM, and chemistry, in order of decreasing frequency of responses. Figure 9 shows a bar graph indicating the response categories of the participants, based on percentage of responses recorded.

\section{Discussion}

The first survey question, "What was your favorite part of the activity?", elicited the largest number of responses in the categories of participation, experimentation, and creation, as shown in 


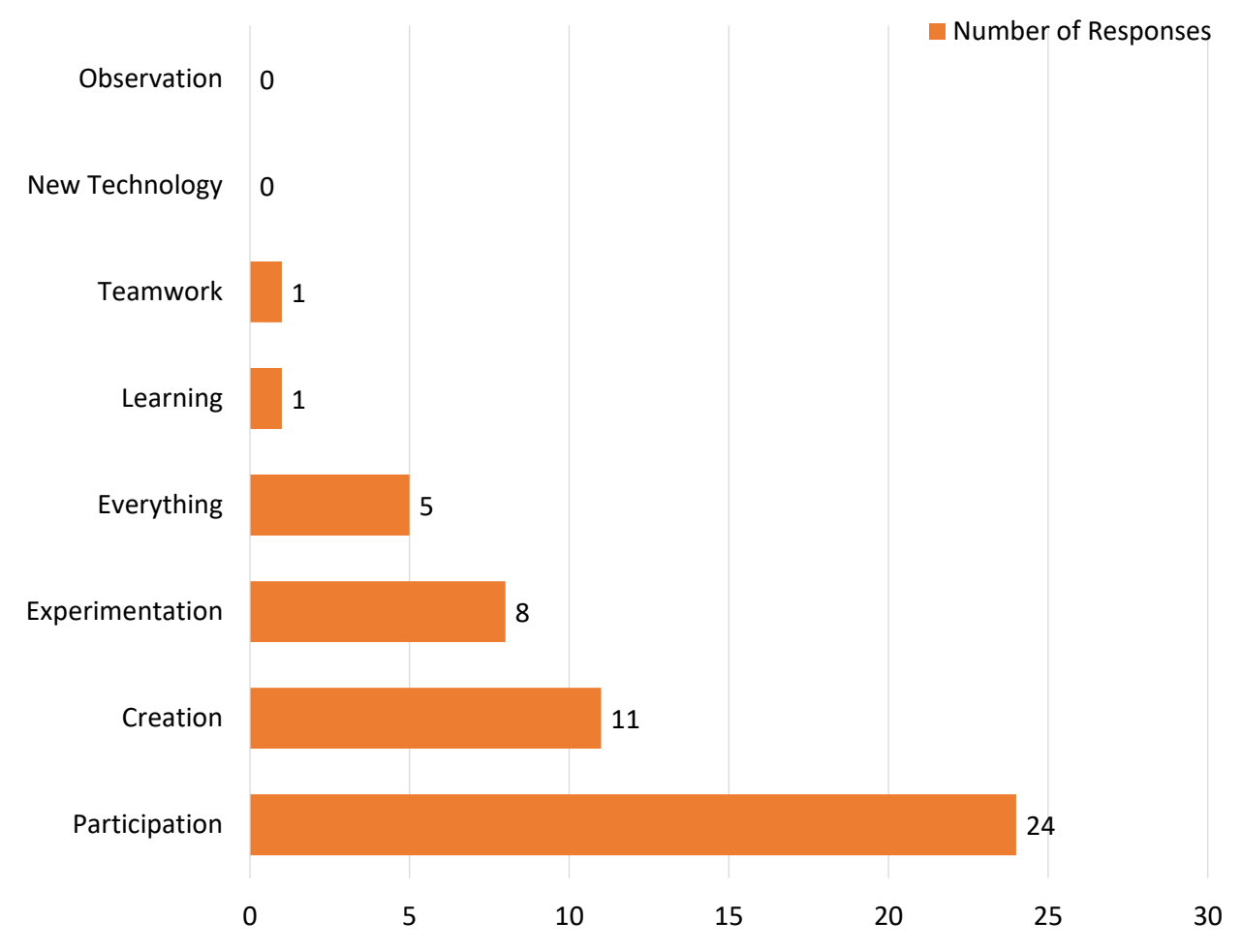

\section{Figure 5: What was your favorite part of the "Fun With Circuits" activity?}

Figures 5 and 6 . These categories combined amount for $68 \%$ of the responses in the Autonomous Vehicles activity, and $86 \%$ of the responses in the Fun With Circuits activity. From these results it can be inferred that the participants enjoyed the hands-on, inventive, and problem-solving aspects of the activities. These results are consistent with previous studies which show that girls particularly appreciate hands-on STEM activities.

By review of Figures 5 and 6, it can be seen that there is a greater variety of response categories for the Autonomous Vehicles activity compared to the Fun With Circuits activity. In general, written responses from the Fun With Circuits activity were short, succinct, and did not reference many specific details relating to the experiment. Examples of such responses include "Making lights", "The experiments", and "making circuits". While there were some exceptions, the majority of responses were short and non-descriptive, suggesting an activity that was less impactful. Written responses from the Autonomous Vehicles activity reveal that the students enjoyed the activity more, and they were also more engaged with it. The responses were more thoughtful, with greater variety. While many of the answers were still fairly short, which can probably be attributed to the demographic surveyed, they were noticeably more substantial than the previous year, with examples such as "My favorite part was being able to make my own line, and test it", "Drawing the lines then seeing the car move on it", and "Testing out the car with lines, and curves, and making hypothesis \& conclusions". While there were some exceptions to this norm, the majority of responses were longer and more descriptive, which suggests an impactful activity. This trend continued in the responses to the second survey question. 


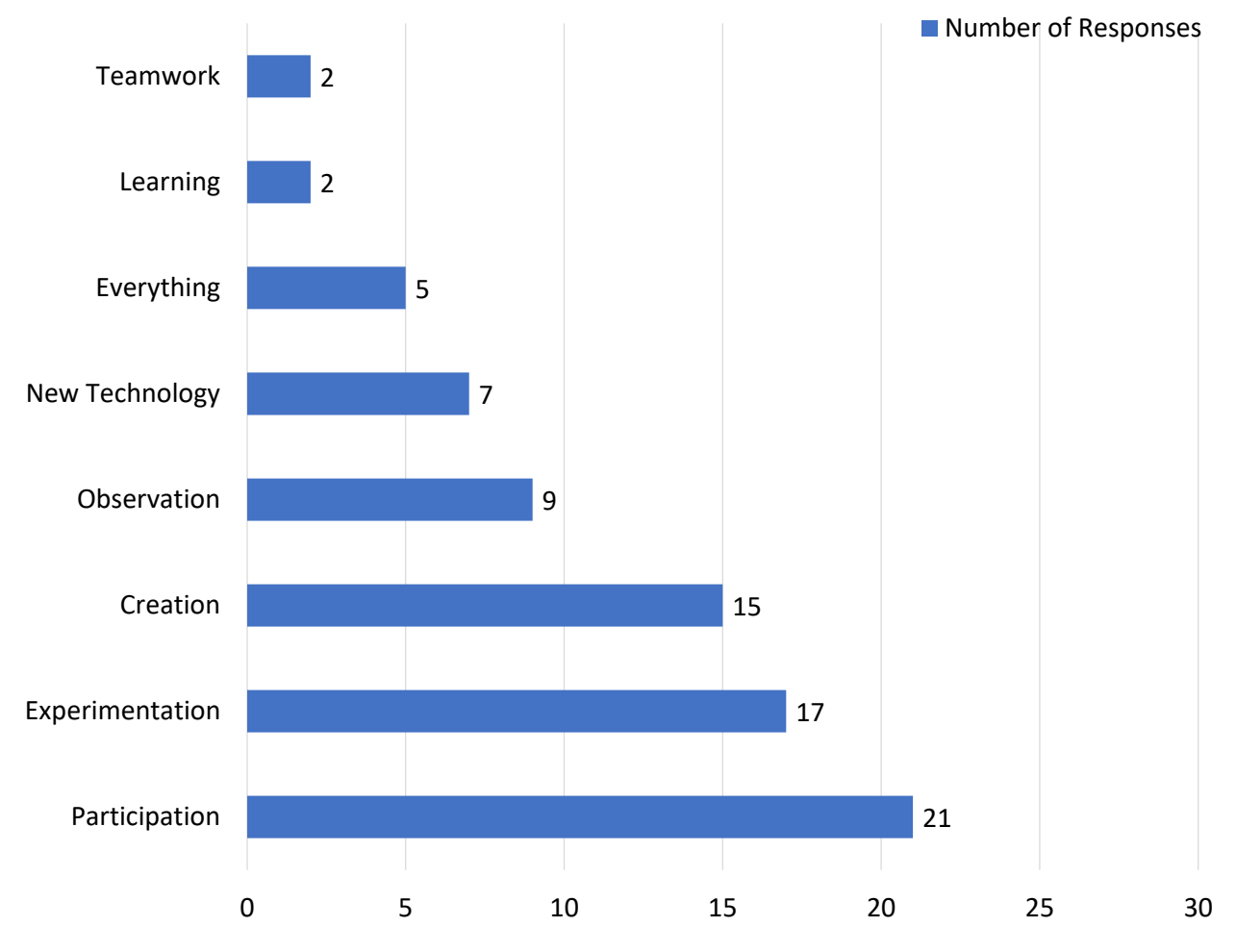

Figure 6: What was your favorite part of the "Autonomous Vehicles" activity?

The second survey question, "What should be changed to make the activity more fun?", gave the participants a chance to express anything that they felt could improve the activity. Results from the second question appear in Figures 7 and 8. From a review of the responses from the Fun With Circuits activity, it can be seen that the girls had many complaints, with a majority of the responses asking for the activity to be modified. Many participants asked for more circuits to be incorporated into the activity, with less "boring worksheets"; they seemed to require a more challenging activity, with only a few responses stating that they have nothing they wish to change. The responses for the Autonomous Vehicles activity had a significant increase in the number of participants that said there were no changes that needed to be made to the activity, jumping from $8 \%$ to over $23 \%$ of the responses. Additionally, the responses from the Autonomous Vehicles activity exhibited a great deal of variety; most of the suggestions related to expanding on the ideas introduced by the activity. Some participants wanted more time to complete the activity, while others wanted to make the activity competitive, but the majority of responses suggested adding extensions to an already engaging activity.

The third survey question, "What subjects would you need to study in college in order to design an autonomous vehicle?", was unique to the Autonomous Vehicles activity. Results from the third question appear in Figure 9; the results show that the Autonomous Vehicles activity had the intended effect on the girls, which was to impress on them the idea that paths to STEM careers involve STEM undergraduate education. Fully $37 \%$ of the responses indicated that engineering should be studied in order to design autonomous vehicles, and all of the other responses were appropriate as well, as they were all STEM related. 
Table 5: Categories for Survey Question 2: What should be changed to make the activity more fun?

\begin{tabular}{lll}
\hline Category & $\begin{array}{l}\text { "Fun With Circuits" Sample } \\
\text { Responses }\end{array}$ & $\begin{array}{l}\text { "Autonomous Vehicles" Sample } \\
\text { Responses }\end{array}$ \\
\hline Enhance Teamwork & $\begin{array}{l}\text { "Connect yours and one from another } \\
\text { group." }\end{array}$ & "More partners." \\
\hline Extend Activity & $\begin{array}{l}\text { "There should be more things not just } \\
\text { lightbulbs. You should have a radio to } \\
\text { connect." }\end{array}$ & $\begin{array}{l}\text { "Creative templates for the car to do } \\
\text { (challenging designs instead of lines)." }\end{array}$ \\
\hline Improve Hardware & $\begin{array}{l}\text { "More lights and batteries so there is } \\
\text { more light." }\end{array}$ & $\begin{array}{l}\text { "What should be changed is that the } \\
\text { sensors should be able to see more } \\
\text { than black." }\end{array}$ \\
\hline Increase Difficulty & "To make it harder, to make an alarm." & "Making the tracks more difficult." \\
\hline No Change & "Nothing because all of it was fun." & $\begin{array}{l}\text { "I don't think anything should change } \\
\text { I thought it was perfect." }\end{array}$ \\
\hline
\end{tabular}

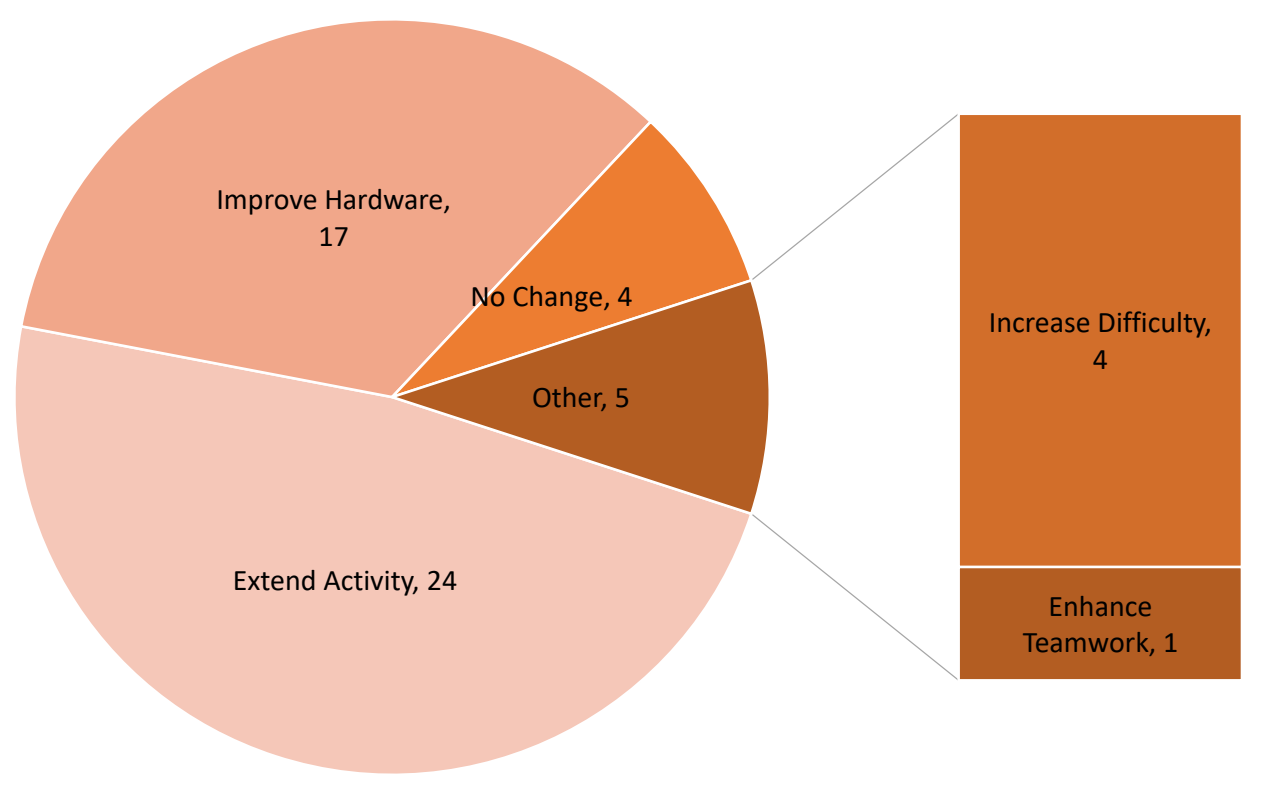

Figure 7: What should be changed to make the "Fun With Circuits" activity more fun? 


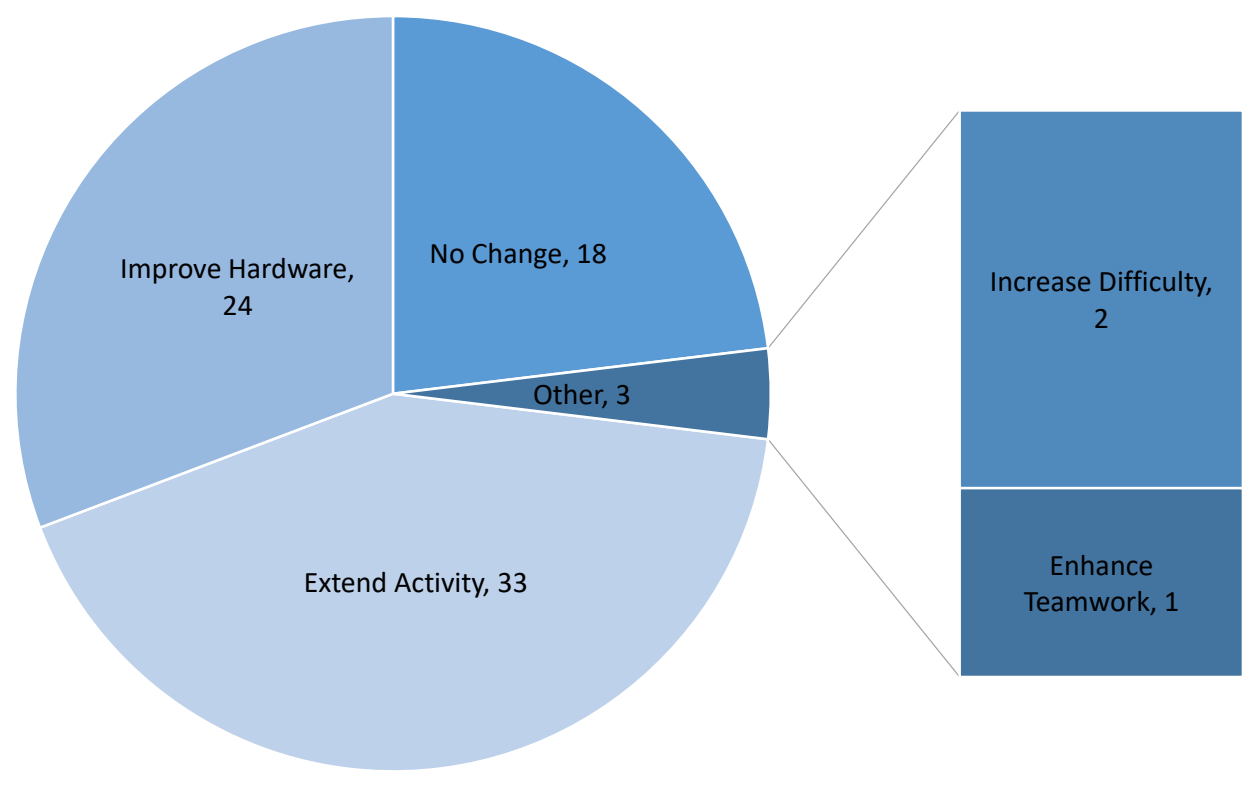

Figure 8: What should be changed to make the "Autonomous Vehicles" activity more fun?

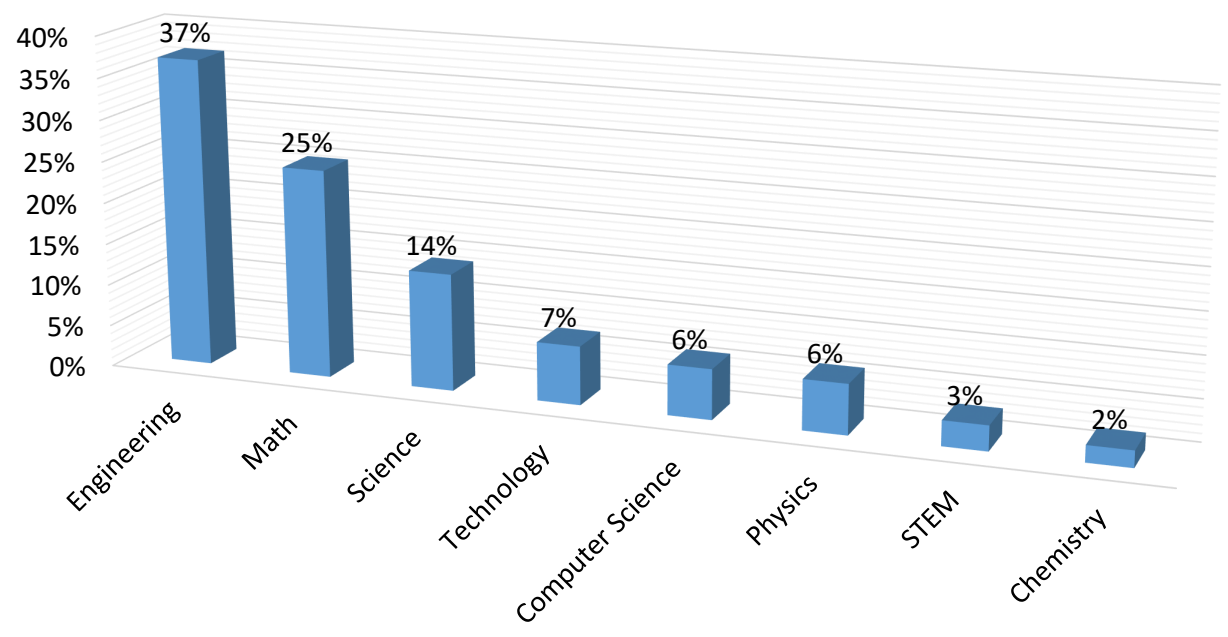

Figure 9: What subjects would you need to study in college in order to design an autonomous vehicle? 


\section{Conclusions and Recommendations}

The results of this work demonstrate that the Autonomous Vehicles activity was successful, in both engaging the girls and in introducing them to a STEM field that requires STEM undergraduate education. Results show that the girls successfully identified STEM undergraduate programs as a requirement for participation in the autonomous vehicles workforce. The supportive environment of GEE, including all-day access to female engineering mentors, is likely to be associated with this success.

Subsequent studies may measure the overall effect of the GEE event, rather than investigate the effectiveness of one or two specific STEM activities that are part of it. Does interest in STEM increase in participating girls from after the event compared to before the event? Further research in this area would also benefit from an analysis of the long-term influence of the GEE event. Are girls who participate in GEE more likely to pursue undergraduate education in STEM fields? Are they more likely to have STEM occupations? Such investigations could provide valuable insight into why women and minorities remain under-represented in STEM fields.

\section{Acknowledgment}

The authors wish to thank Kosciuszko Gilbert and Peter Parsons, two undergraduate students at Kettering University who helped with the survey data analysis. We would also like to thank Theresa Atkinson, Assistant Professor of Mechanical Engineering at Kettering University, for providing the idea for the autonomous vehicles activity. Finally, we would like to express our gratitude to all of the volunteers who make SWE GEE possible.

\section{References}

[1] J. Bossart and N. Bharti, "Women in engineering: Insight into why some engineering departments have more success in recruiting and graduating women," American Journal of Engineering Education, vol. 8, no. 2, pp. 127-140, 2017.

[2] "Record number of female first-year students join Canada's top-ranked engineering school," Canada NewsWire, January 28, 2015.

[3] "Black degree attainments in engineering," Journal of Blacks in Higher Education, August 2, 2012, [Online], Available:

https://www.jbhe.com/2012/08/black-degree-attainments-in-engineering/, Accessed Mar. $17,2019$.

[4] L. Su, "Promoting diversity in engineering," Mechanical Engineering, vol. 123, no. 5, p. 32, 2001.

[5] J. G. Stout, V. A. Grunberg, and T. A. Ito, "Gender roles and stereotypes about science careers help explain women and men's science pursuits," Sex Roles, vol. 75, no. 9-10, pp. 490-499, 2016. 
[6] R. A. Atadero, C. H. Paguyo, K. Rambo-Hernandez, and H. L. Henderson, "Building inclusive engineering identities: Implications for changing engineering culture," European Journal of Engineering Education, vol. 43, no. 3, pp. 378-398, 2018.

[7] M. Ismail, N. Zulkifli, and S. R. Hamzah, "Insights on engineering as a non-traditional career field for women," Global Business and Management Research, vol. 9, no. 4, pp. 17-36, 2017.

[8] M. Ing, "Gender differences in the influence of early perceived parental support on student mathematics and science achievement and STEM career attainment," International Journal of Science and Mathematics Education, vol. 12, no. 5, pp. 1221 - 1239, 2014.

[9] G. Knezek, R. Christensen, T. Tyler-Wood, and D. Gibson, “Gender differences in conceptualizations of STEM career interest: Complementary perspectives from data mining, multivariate data analysis and multidimensional scaling," Journal of STEM Education, vol. 16, no. 4, pp. 13 - 19, 2015.

[10] E. Gunderson, G. Ramirez, S. Levine, and S. Beilock, "The role of parents and teachers in the development of gender-related math attitudes," Sex Roles, vol. 66, no. 3, pp. 153 - 166, 2012.

[11] S. Guzey, T. Moore, M. Harwell, and M. Moreno, "STEM integration in middle school life science: Student learning and attitudes," Journal of Science Education and Technology, vol. 25 , no. 4 , pp. $550-560,2016$.

[12] K. Lee and J. Anderson, "Who is really interested in mathematics? An investigation of lower secondary students' mathematical role models," in Proceedings of the $37^{\text {th }}$ Annual Conference of the Mathematics Education Research Group of Australasia, Sydney, Australia, 2014.

[13] R. Hughes, B. Nzekwe, and K. Molyneaux, "The single sex debate for girls in science: A comparison between two informal science programs on middle school students' stem identity formation," Research in Science Education, vol. 43, no. 5, pp. 1979 - 2007, 2013.

[14] J. Schnittka and C. Schnittka, "Can I drop it this time? Gender and collaborative group dynamics in an engineering design-based afterschool program," Journal of Pre-College Engineering Education Research, vol. 6, no. 2, pp. 1 - 24, 2016.

[15] V. Wyss, D. Heulskamp, and C. Siebert, "Increasing middle school student interest in STEM careers with videos of scientists," International Journal of Environmental \& Science Education, vol. 7, no. 4, pp. 501 - 522, 2012.

[16] M. Levine, N. Serio, B. Radaram, S. Chaudhuri, and W. Talbert, "Addressing the STEM gender gap by designing and implementing an educational outreach chemistry camp for middle school girls," Journal of Chemical Education, vol. 92, no. 10, pp. 1639 - 1644, 2015.

[17] H. Kim, "Inquiry-based science and technology enrichment program for middle school-aged female students," Journal of Science Education and Technology, vol. 25, no. 2, pp. 174 186, 2016. 
[18] R. Christensen and G. Knezek, "Relationship of middle school student STEM interest to career intent," Journal of Education in Science, Environment and Health, vol. 3, no. 1, pp. 1 $-13,2017$.

[19] E. Tan, A. Barton, H. Kang, and T. O’Neill, “Desiring a career in STEM-related fields: How middle school girls articulate and negotiate identities-in-practice in science," Journal of Research in Science Teaching, vol. 50, no. 10, pp. 1143 - 1179, 2013.

[20] T. Tyler-Wood, A. Ellison, O. Lim, and S. Periathiruvadi, "Bringing up girls in science (BUGS): The effectiveness of an afterschool environmental science program for increasing female students' interest in science careers," Journal of Science Education and Technology, vol. 21, no. 1, pp. $46-55,2012$.

[21] "Educational inequality," Black Life, Arts \& Culture, January 4, 2016, [Online], Available: http://www.blacdetroit.com/BLAC-Detroit/January-2016/Educational-Inequality, Accessed Mar. 17, 2019.

[22] [Online], Available: https://www.mi-sci.org/, Accessed Mar. 17, 2019.

[23] "Hands-on activity: Completing the circuit," TeachEngineering STEM Curriculum for K-12, [Online], Available:

https://www.teachengineering.org/activities/view/cub_electricity_lesson03_activity1, Accessed Mar. 17, 2019.

[24] D. R. Thomas, "A general inductive approach for analyzing qualitative evaluation data," American Journal of Evaluation, vol. 27, no. 2, pp. 237 - 246, 2006. 


\section{Appendix A}

Handouts for two STEM activities are provided, Fun With Circuits and Autonomous Vehicles, including worksheets and science sheets. 


\section{“Fun With Circuits" Activity - Worksheet}

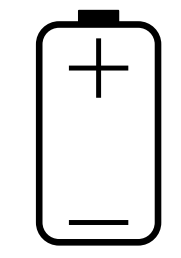

(a) Battery

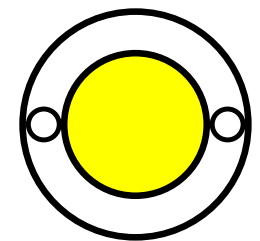

(b) Light Bulb (c) Wire

Figure 1: Electrical Symbols for Circuit Drawings

\section{Your name.}

Draw a way to connect one light bulb $\bar{\nearrow}$, the battery and wires so the bulb will light up. Use the symbols provided.

What must you do to get the bulb to light up?

What do you notice about the brightness of the one light? 
Draw a way to connect two light bulbs in series (one after the other in a chain) so both bulbs will light up. Use the symbols provided.

What do you notice about the brightness of the two lights?

Choose the best answer to complete the sentence.

There will be an electric current in circuit.
(A) an open
(B) a closed
(C) a big
(D) a long

Choose the best answer to complete the sentence.

If more light bulbs are connected together in series then:
(A) they will be brighter than one bulb alone.
(B) they will have the same brightness as one bulb alone.
(C) they will be dimmer than one bulb alone. 


\section{"Fun With Circuits" Activity - Science}
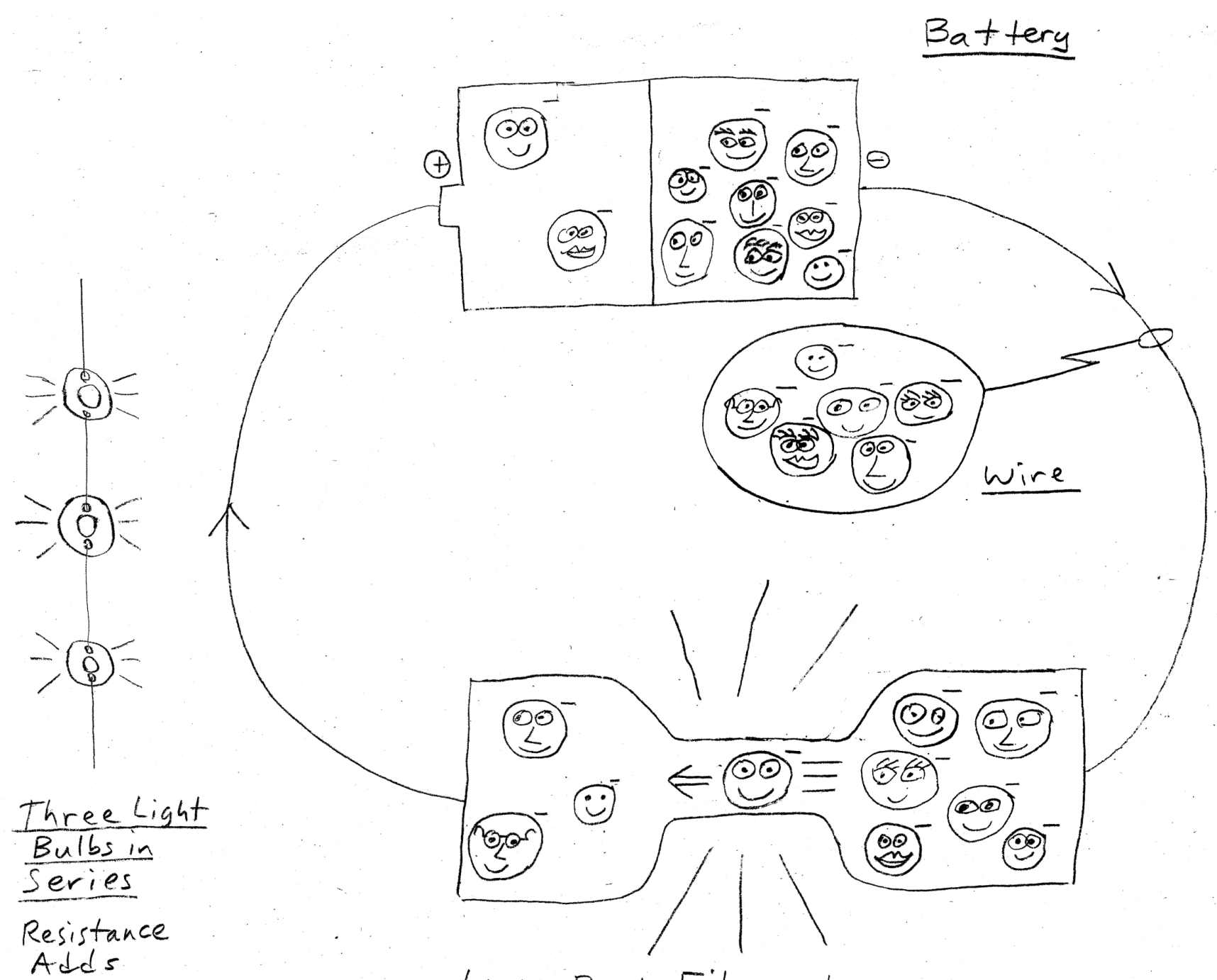

Light Bulb Filament

Figure 1: Sketch of Closed Electric Circuit With One Light Bulb

How does the light bulb circuit work?

There is a battery at the top of the circuit in Figure 1. A battery is a container that holds special chemicals for generating electricity. Its chemical action causes electrons to collect together in one part of the battery, with a barrier preventing them from reaching the other part of the battery.

Think of it this way: the battery is like a really strange house. Imagine that one side of the house has all of the bedrooms, and all of the electrons are in that side just waking up in the morning. On the other side of the 
house is the kitchen where breakfast is being served. The bedroom side of the house, with all of the electrons, is called the anode. The kitchen side of the house is called the cathode.

Normally you would go straight from your bedroom to the kitchen to get breakfast, but in this strange house there is a thick wall separating the house into two parts. The electrons cannot travel through the wall; they need to take a different path to get to their breakfast.

The electrons can only travel on a path called a conductor, as shown in Figure 2. Conductors are materials that electrons can move through, such as metals. The electrons need a conductor, or path, to get to the kitchen. This path is also called a circuit; the word circuit comes from the Latin word circuitus, meaning "going around". The circuit that the electrons need to move on will be going around from the bedrooms to the kitchen. Therefore, in the strange house the electrons

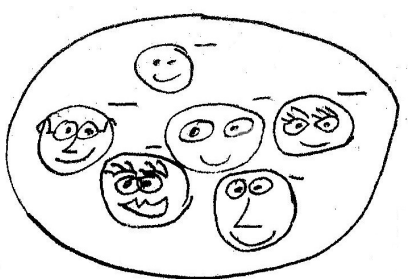

Figure 2: Electrons in Conductor must leave their house and travel outside of it on a circuit to get to their breakfast.

The circuit consists of metal wires that connect the bedroom side of the house to the kitchen side. If you connected a metal wire directly from the anode (bedrooms) to the cathode (kitchen), then all the electrons would zoom over to the kitchen quickly.

But what if a person puts something into the circuit that the electrons have to pass through on their way from the bedrooms to the kitchen? This is like having chores to do in the morning after you wake up but before you can have breakfast. Can we make the electrons do chores for us as they pass through the circuit?

This is what happens when we put a light bulb into the circuit. Inside the light bulb is a very thin metal wire called a filament. The filament resists the movement of electrons. When the electrons travel through the light bulb filament, both heat and light are produced.

The light bulb acts as a resistor. When resistors are connected in series, their resistance adds up. Therefore, there is more resistance in a circuit with more light bulbs chained together. Each light bulb will be dimmer in comparison to a circuit that has fewer bulbs. A circuit with just one light bulb will produce the brightest light. 


\section{Autonomous Vehicles Activity - Worksheet}

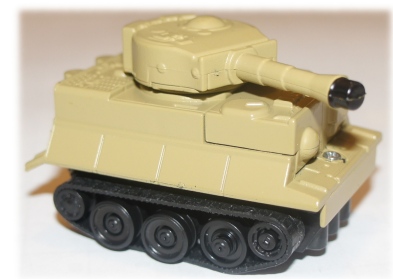

(a) Toy Tank

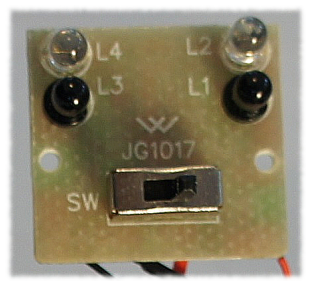

(b) Sensor Inside Tank

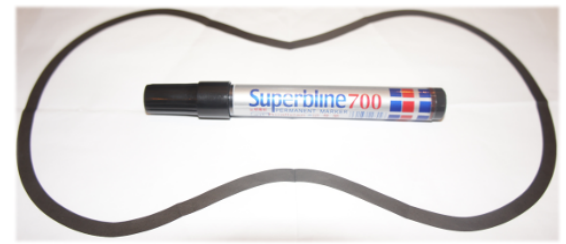

(c) Road Lines for Tank

Figure 1: Autonomous Vehicle, Optical Sensor, and Hand-Drawn Roadway

\section{Student Name}

(1) Draw six straight, parallel lines as illustrated below, about a handwidth apart. Use the pens and paper provided.

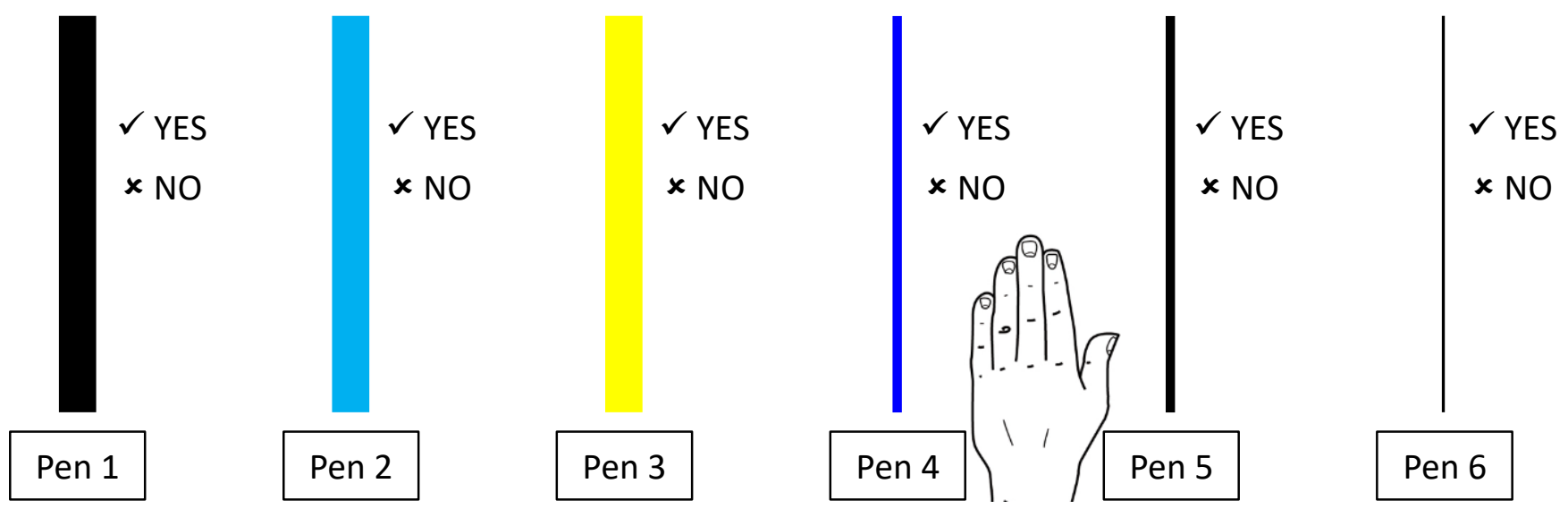

(2) Test the vehicle to find out if it can follow each straight line. Circle "yes" or "no" at the right side of each line, depending on whether the vehicle can follow the line or not.

(3) Which pens work best with the vehicle? Write the best pen numbers below. What do the best pen lines have in common? 
(4) Draw five curved lines as illustrated below, about a hand-width apart. Use the best pens and paper provided.

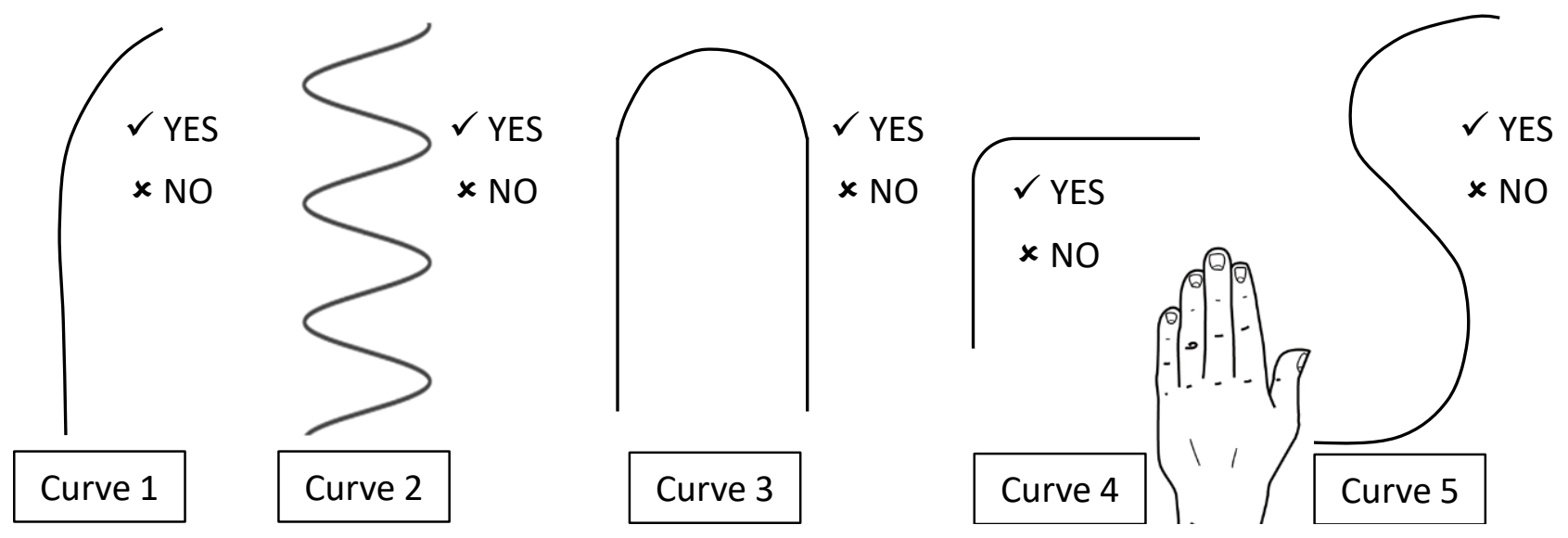

(5) Test the vehicle to find out if it can follow each curved line. Circle "yes" or "no" at the right side of each line, depending on whether the vehicle can follow the line or not.

6) Draw several lines of your choice. Suggested lines include dashed, dotted or solid with alternating colors. Use the pens and paper provided. Test the vehicle to find out if it can follow each line.

(7) Overall, does the autonomous vehicle perform well? Explain your answer.

8 What design changes could be made to the autonomous vehicle to improve its performance? 


\section{Autonomous Vehicles Activity - Science}

\section{How do autonomous vehicles work?}

An autonomous vehicle is a self-driving vehicle that is capable of traveling on city streets and highways without input from a human being. The control inputs to the vehicle, such as turning the steering wheel or pressing the brake pedal, are made by the vehicle itself, not by a human person riding inside the vehicle. A photograph of the Kettering University "Bulldog Bolt" autonomous vehicle at the 2018 North American International Auto Show is shown in Figure 1. This vehicle is being developed as part of the AutoDrive Challenge ${ }^{\mathrm{TM}}$, which is a SAE (Society of Automotive Engineers) Collegiate Design Series.

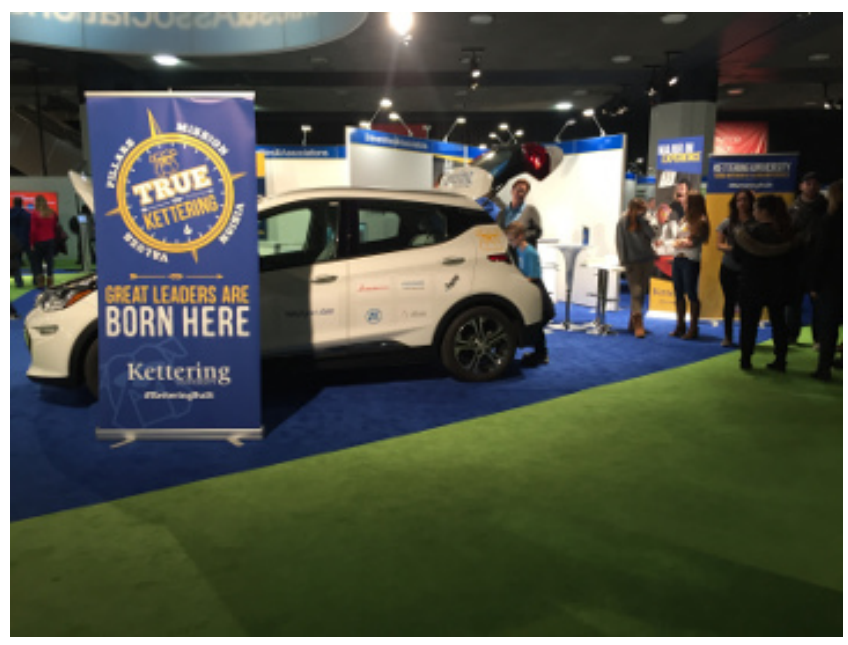

(a) Booth Display

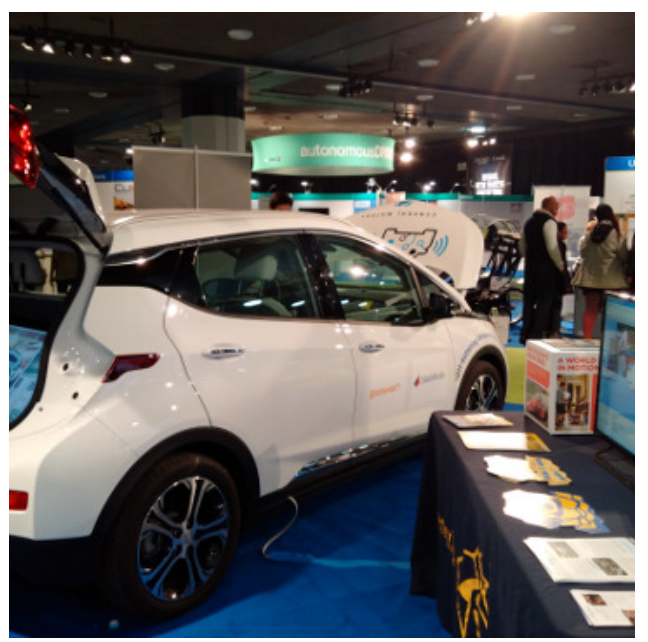

(b) Detail of Car

Figure 1: Kettering University Autonomous Vehicle

An autonomous vehicle needs to have systems that replace the function of human systems. For example, an autonomous vehicle must have "eyes" that can see the road. An autonomous vehicle uses special sensors to see the road lane markings and road signs. Below is a list of sensor types that are commonly used as the eyes of an autonomous vehicle.

1. Camera - Photographs are created that can be examined to classify objects that are in the field of view, like pedestrians and stop signs.

2. LIDAR (LIght Detection And Ranging) - Light waves from a laser beam are used to measure the distance from objects.

3. RADAR (RAdio Detection And Ranging) - Radio waves are used to detect the location and speed of objects, especially for things that are far away.

An autonomous vehicle must also have a "brain" that can process the information from the sensors. In practice, a powerful on-board computer is used to reason about the data gathered from the sensors. The autonomous vehicle uses its computer system to learn about its surroundings and make decisions about what to do on the road. 


\section{How does the autonomous toy vehicle work?}

The autonomous toy vehicle has an optical sensor system that can see the road lines. These lines are drawn using a black marker. The black road lines present a large visual contrast to the optical sensor, compared to the white background of the paper. The contrast between the road markings and the road are similar to - but opposite from - the real world, where the road is black and the road markings are white. A photograph of the toy autonomous vehicle is shown in Figure 2.

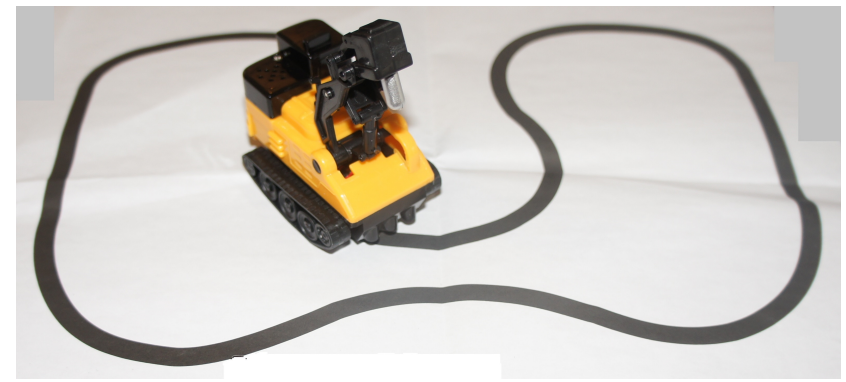

(a) Toy Construction Vehicle on Road Course

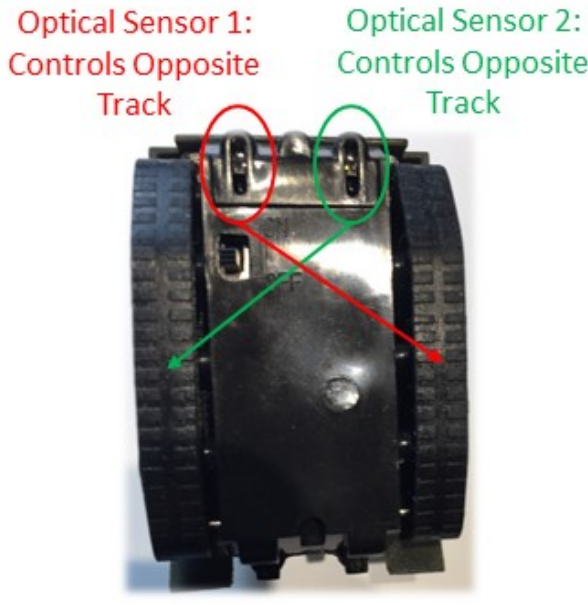

(b) Detail of Underside

Figure 2: Toy Autonomous Vehicle

The optical sensor system in the toy autonomous vehicle consists of two separate sensors. The road line is centered between the sensors when the vehicle is driving on a straight road. The sensors are sensitive to light and dark; each sensor controls one of the tracks. When the light to one of the sensors is interrupted, such as by a dark road line, the opposite track stops moving, but the other track continues to move. Thus, the toy autonomous vehicle turns by using a "differential steering" principle, where the wheels on one side of the vehicle move faster than the wheels on the other side in order to turn the vehicle. This is a common type of steering system in bulldozers and tanks, but it is not normally used in family cars and pickup trucks.

\section{Brain Teaser}

When the toy autonomous vehicle is confused about the whereabouts of the road, it goes into a default mode where it travels in circles in one place. What do you think about this as a strategy for when an autonomous vehicle is lost or confused? What would happen if a real autonomous vehicle started driving around in circles in the middle of the highway if it was confused about its location? What would be a better thing for an autonomous vehicle to do if it was confused? How would you answer this question if you were an engineer working on an autonomous vehicle development project? 